\title{
Tumor Microembolism to Alveolar Capillaries
}

\author{
Yoshiaki Kinoshita ${ }^{1}$, Hiroshi Ishii ${ }^{1}$, Hisako Kushima ${ }^{1}$ and Kentaro Watanabe ${ }^{1,2}$
}

Key words: ground-glass attenuation, breast cancer, embolus

(Intern Med 58: 2899-2900, 2019)

(DOI: 10.2169/internalmedicine.2934-19)

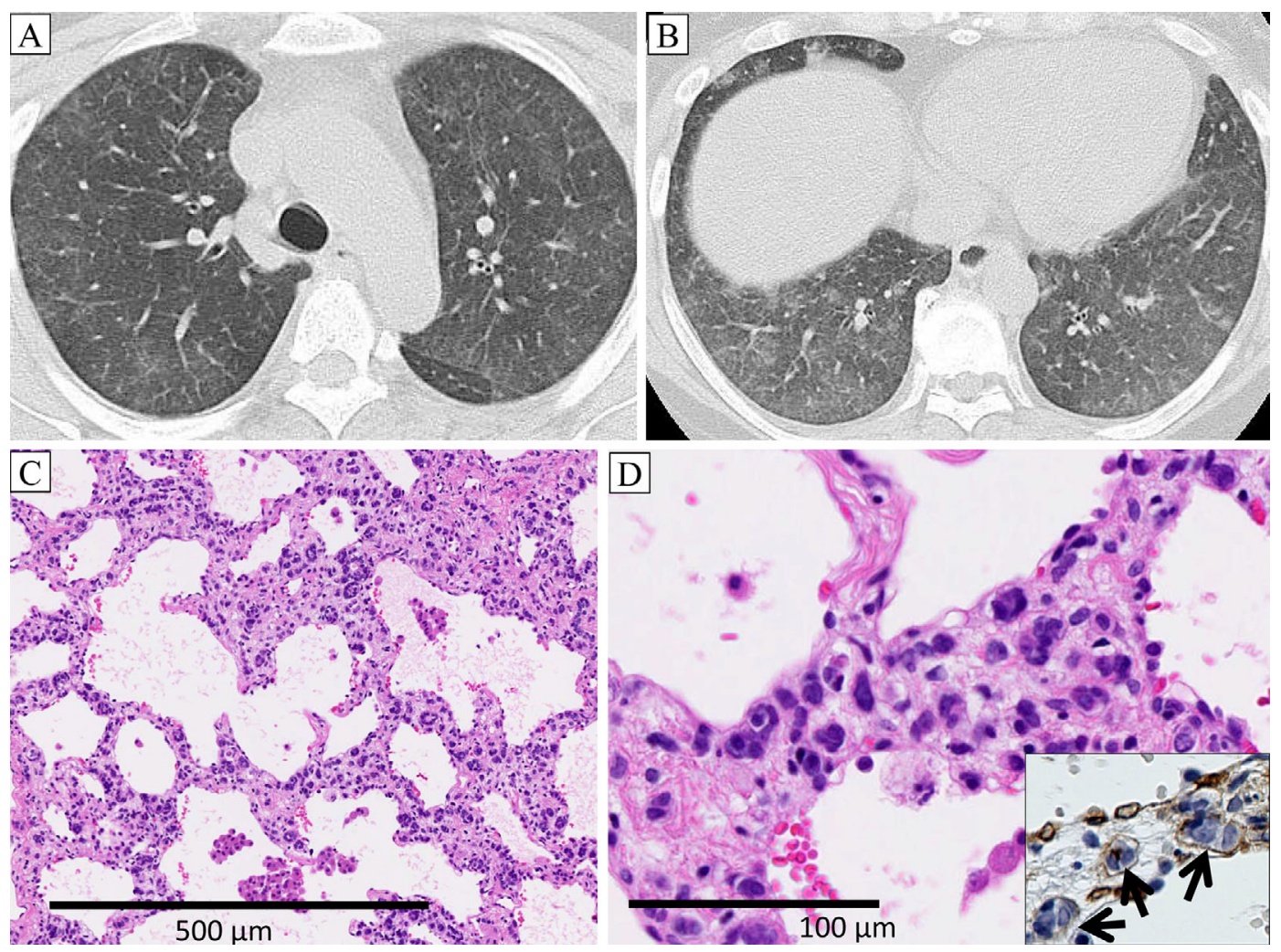

Picture.

A 45-year-old woman presented with persistent dyspnea on exertion. Two months earlier, she had undergone surgical resection for breast cancer. Chest computed tomography showed diffuse ground-glass attenuation (Picture A and B). The interlobular septa and bronchovascular bundles were inconspicuous. A surgical lung biopsy was performed, and an examination of the biopsy specimens showed diffuse thickening of the alveolar walls (Picture C and D). Immunohistochemistry revealed diffuse microemboli with atypical cells occluding CD34-positive pulmonary capillaries (Picture D, inset; arrows). The origin of the tumor cells was immunohis- tochemically confirmed to be breast cancer. She received chemotherapy and hormonal therapy. The ground-glass attenuation completely disappeared three months after the treatment. Although tumor microembolism to alveolar capillaries is a rare complication of malignancies (1), clinicians should be aware of this form of metastasis in cancer patients. An early diagnosis may allow time for treatment that may improve the outcome.

The authors state that they have no Conflict of Interest (COI).

${ }^{1}$ Department of Respiratory Medicine, Fukuoka University Hospital, Japan and ${ }^{2}$ General Medical Research Center, Fukuoka University School of Medicine, Japan

Received: March 1, 2019; Accepted: April 1, 2019; Advance Publication by J-STAGE: June 7, 2019

Correspondence to Dr. Hiroshi Ishii, hishii@fukuoka-u.ac.jp 


\section{Reference}

1. Soares FA, Landell GA, de Oliveira JA. Pulmonary tumor embolism to alveolar septal capillaries. An unusual cause of sudden cor pulmonale. Arch Pathol Lab Med 116: 187-188, 1992.
The Internal Medicine is an Open Access journal distributed under the Creative Commons Attribution-NonCommercial-NoDerivatives 4.0 International License. To view the details of this license, please visit (https://creativecommons.org/licenses/ by-nc-nd/4.0/).

(C) 2019 The Japanese Society of Internal Medicine Intern Med 58: 2899-2900, 2019 